\title{
The stigmatisation of people with chronic back pain
}

Immy Holloway ${ }^{\mathrm{a},}$ Beatrice Sofaer-Bennett ${ }^{\mathrm{b}}$, Jan Walker ${ }^{\mathrm{c}}$,

In press in Disability and Rehabilitation

${ }^{a}$ Institute of Health and Community Studies, Bournemouth University

Christchurch Rd, Bournemouth BH1 3LT

${ }^{\mathrm{b}}$ Clinical Research Centre for Health Professions, University of Brighton, East

Sussex, BN20 7UR, UK

${ }^{c}$ Faculty of Medicine, Health and Life Sciences, Building 67, University

Southampton, Highfield, Southampton, SO17 1BJ, UK

Correspondence to:

Professor I. M. Holloway

Institute of Health and Community Studies

Bournemouth University

Royal London House

Christchurch Rd

Bournemouth BH1 3LT

Tel: 01202962168

Fax: 01202962194 
Key words: chronic back pain, stigma, interviews, qualitative research

Word count (body): 5567

Word count (abstract): 229 


\section{TITLE: The stigmatisation of people with chronic back pain}

\section{ABSTRACT}

Purpose. This study responded to the need for better theoretical understanding of experiences that shape the beliefs, attitudes and needs of chronic back patients attending pain clinics. The aim was explore and conceptualise the experiences of people of working age who seek help from pain clinics for chronic back pain.

Methods. This was a qualitative study, based on an interpretative phenomenological approach (IPA). During in-depth interviews in their homes, participants were invited to 'tell their story' from the time their pain began.

Participants were twelve male and six female patients, aged between 28 and 62 years, diagnosed as having chronic benign back pain. All had recently attended one of two pain clinics as new referrals. The interview transcripts were analysed thematically.

Findings. Stigmatisation emerged as a key theme from the narrative accounts of participants. The findings expose subtle as well as overt stigmatising responses by family, friends, health professionals and the general public which appeared to have a profound effect on the perceptions, self esteem and behaviours of those interviewed.

Conclusions. The findings suggest that patients with chronic back pain feel stigmatised by the time they attend pain clinics and this may affect their attitudes and behaviours towards those offering professional help. Theories of chronic pain 
need to accommodate these responses, while pain management programmes need to address the realities and practicalities of dealing with stigma in everyday life. 


\section{Introduction}

Chronic back pain is a complex multifactorial problem influenced by contextual demands and coping responses [1]. Recent authors [2, 3] have identified that attempts to develop psychological models to conceptualise pain and its management have tended to overlook the unique situational demands and changes faced by chronic pain patients in their everyday lives. Although Ericsson et al [4] eliminated personality as a potential cause of the depression commonly associated with chronic pain, they failed to explore contributory factors from the social environment. Social interactions, whether with professionals or family or friends, are important since they help to shape the expectations, perceived needs and responses of those attending pain clinics. The purpose of the present study was to explore the experience of chronic back pain within the everyday lives of patients, up to the point of seeking help from pain clinics. In so doing, we specifically wished to avoid the evaluation of pain treatments and focus instead on the experiences that have helped to shape patients' needs at the point of entry to pain services.

Prior to the conduct of the study, only a few in depth qualitative studies on the topic of chronic back pain were identified. Bowman $[5,6]$ focused predominantly on the experience of attending a pain management programme. Two studies were designed primarily to supplement data from clinical intervention studies for back pain $[7,8]$ and confirm various negative impacts of pain on daily living and lifestyle which are clearly worthy of further investigation. A fourth, described as a 
pilot study [9], began to capture the enormity of the difficulties faced by back pain patients in their daily lives. Subsequently, Lillrank [10] has reported on findings from the written narratives of 30 Finnish women about the difficulties in getting back pain diagnosed, while Ong et al. [11], reporting on qualitative aspects of a longitudinal mixed-methods study of low back pain, focused primarily on the social construction and presentation of self. Of direct relevance to the present article is the narrative interview study of women with chronic pain by Werner and colleagues $[12,13]$. Though small scale $(\mathrm{N}=10)$, these authors went beyond the analysis of narrative content to consider the pain story as a performance designed to convince the researchers of the legitimacy of pain and suffering. In so doing, the authors questioned the extent to which their findings were genderspecific. The present study collected narratives from both men and women. Important themes to emerge included 'in the system' which concerned patients' encounters with health care, social security and legal systems [14] and 'loss' which referred to the catalogue of physical, psychological and social losses experienced as a direct result of having pain [3]. In this paper we focus specifically on the core theme to emerge, that of 'stigmatisation'.

\section{Method}

\section{Design}

We used an interpretative phenomenological approach (IPA) $[15,16]$. The aim of IPA [17] is 'to explore ... how participants are making sense of their personal and social worlds' and how this experience affects their everyday life. The data were 
collected using in-depth, audio-taped, narrative interviews which provided a platform for individuals to tell their story [11] and sought to eliminate biases that might have been introduced into the data through the use of an interview guide.

\section{Sample}

IPA relies on purposive sampling, that is, the choice of sample depends on the experience of the phenomenon or condition. The sample consisted of twelve male and six female patients, all of whom had recently been assessed as new referrals at one of two pain clinics in the south of England and had a confirmed diagnosis of chronic benign back pain. This ensured that participants shared pain-related problems and were at similar points in their pain careers in terms of medical help-seeking. All were under 65 years but only one woman remained in full-time or permanent employment. We deliberately selected a heterogeneous mix of experiences according to gender, age, duration of pain, and social background as judged by former occupation and home location. Participants appeared fairly typical of referrals from the two chosen localities: all were British

and their ages ranged from 28 to 62 years, median 53 years. The duration of pain was two to 22 years, median 6 years (one participant had experienced intermittent bouts of pain over many years). All had experienced a variety of treatments for back pain prior to their referral to the pain clinic.

\section{Procedure}

The study received research ethics approval. Audio-taped interviews, lasting 
between one and a half and three hours, took place by appointment in participants' own homes, enabling them to feel relaxed and providing the researchers with the opportunity to record field notes about the home context. Following the tradition of Kleinman [18], a narrative approach was used whereby participants were invited to 'tell their story' of back pain from the time the pain started and encouraged to elaborate on salient feelings or experiences using prompts such as 'tell me a bit more about that', 'how do you feel about that?'. Where specific questions arose, these were deferred until the end of the interview to avoid introducing bias into the data. The interviews were transcribed verbatim but pseudonyms used throughout and analysed in accordance with IPA [17].

\section{Data analysis}

Immersion in the text is the most important aspect of the analysis, and researchers need to be intimate with the data, but for Smith the approach is not prescriptive as long as it is true to the tenets of qualitative research. As we followed the words of the interviewees, we became aware of the significant patterns and contradictions inherent in the interviews. Field notes discussed earlier also became part of the analysis. The contents of the tapes and transcripts were listened to and read through several times and initial notes were made in order to capture a full impression of the data. Chunks of text were extracted that encountered during their pain histories [19]. Recurrent or prominent themes were identified and linked to common themes across the 
transcripts. These themes emerged from all interviews through participant focus and emphasis. A peer review (reading and analysis of the transcripts by a colleague who was not involved in the interviews) was undertaken to find out whether the themes selected by the two interviewers after initial analysis robustly represented the data available in the transcripts.

\section{Trustworthiness}

Qualitative studies do not set out to produce replicable or reproducible results though the findings should be seen to be credible and trustworthy (valid) in representing the realities of the participant group [20]. Generalisability is dependent on representative sampling and is therefore not applicable to qualitative research. Instead, the term 'transferability' is applied to emergent concepts that are judged to be relevant to other similar settings and situations. This is achieved by comparing the emergent findings with the extant literature, thus enabling the reader to judge if the data can be recontexualised in other similar situations and thereby contribute to the 'greater body of knowledge' [21].

\section{Findings}

The concept of stigmatisation arose directly from the data. Although the participants did not use this specific word directly, all told stories that clearly demonstrated stigmatisation had indeed occurred. In labelling this theme, we drew on the work of Goffman [22] who describes stigma as a discrediting trait. He distinguished between features that are visible to the observer and those which 
the owner attempts to conceal because they are perceived to be discreditable. Both types of stigma were clearly identifiable in the stories of our participants, as illustrated in the quotations we have selected as representative of the participants' experiences. These findings plots the social processes through which these stigma are acquired and the effects these stigma have on the lives of those with chronic back pain. The findings are presented as a series of subthemes related to stigma, in dialogue with the literature as is usual in qualitative research. The quotations selected are those that represent prominent experiences (those emphasised as important by one or more participants) or common types of experience (those shared by different participants). The quotations we have selected are those that represent prominent or shared experiences described by our participants.

\section{Stigmatisation in the health care system}

All participants had received X-rays and MRI scans even though these have been shown to be of limited diagnostic value in back pain [23]. This may be because doctors continue to privilege organic explanations for pain [24], and medical conditions such as chronic pain are not regarded as legitimate if the cause is unknown and treatment of limited value [25]. Diamond and Grauer [26] attributed this to a low tolerance for ambiguity and the need of doctors to feel competent. In those aged over 50 , feedback commonly referred to 'degenerative change'. Jane's understanding of this was fairly typical: 'there was no [intervertebral disc] prolapse; there was no nerve end damage; I was just 
basically falling apart, wearing out. It meant l'd been written off quite honestly'. Age-related explanations may be intended to legitimise the pain or support the benign nature of the condition, but imply progressive deterioration and confer the stigma of the aged body. However, a number of studies have identified that those seeking help from pain clinics have a strong belief in organic pathology and demand biomechanical explanations [27]. In contrast, health care professionals are more likely to draw on a psychological explanations of chronic pain [28] particularly when faced by lack of congruity between pain behaviours and objective medical findings. This can lead professionals to doubt the physical reality and hence the legitimacy of persistent back pain [29, 30]. As a result, sufferers are labelled as 'morally weak' [27]. We refer to this as 'moral stigma'. Accordingly, when medical investigations proved negative, consultants appeared to lose interest and delegated care to junior medical staff. Judith (aged 58) described her experience: 'When you have been in pain for a long time, you don't actually see the consultant. You wait for ages and ages and ages and you come out feeling totally baffled really. He [the doctor] doesn't really seem to understand your problem and you feel like bursting into tears, you have wasted such a lot of time and energy.... You don't feel that you're being treated as a person at all'. Cassell [31] proposed that such attitudes are a consequence of the tendency in western medicine to treat people as objects of medical interest, "like a specimen in a bottle'. The failure to confirm a reason for the pain led participants to feel that a part of their existence had been invalidated. Thus stigma was assigned by the patient to the doctor who was deemed to have failed in the moral duty to 
diagnose and treat; and by the medical profession to the patient who had failed in the moral duty to reveal a credible medical diagnosis or respond to treatment.

The latter perception of this 'moral stigma' is closely related to self-doubt and challenges to personal identity, leading to feelings of disempowerment and shame [32]. As a result, Mike (aged 56) claimed that he avoided visiting his GP for fear of being labelled a hypochondriac. In 1996, an IASP report on back pain attributed chronic benign back pain to 'exercise intolerance' [33]. Possibly as a result of this, seeking medical help for back pain seems to have become imbued with stigma and lack of sympathy. David was aged 46 and lived alone when: ' actually collapsed with my back and it took me an hour to get back up on my feet. Every time I moved I received like a stabbing pain. When I finally got to the telephone to ask for an ambulance to take me to the hospital the ambulance arrived and quite bluntly informed me, well if I can walk to the telephone I can damn well walk to the hospital'. Reg (aged 53) was an in-patient with an acute exacerbation of his back pain when he experienced humiliation at the hands of an orthopaedic surgeon who 'stood in front of four nurses one day and said 'there's nothing wrong with you Mr. C, you're really very unfit'. I felt stupid - the pain isn't in my head it's in my back". Eccleston et al [28] recognised the power of professionals to cause distress in those with chronic pain, though we found little support for their assertion that this is associated with self-blame - as Reg continued: "I'm not swinging the lead to get out of work. It caused a lot of problems and made me feel very inadequate'. It is recognised in the literature on 
the 'sick role' that the task of medicine is to treat and the task of the patient is to get well [34]. As a result, patients who fail to respond to treatment have been recorded as 'unpopular' among nursing staff [35]. Sue, a 28 year-old registered nurse describe her experience after readmission following back surgery for pain later diagnosed as arachnoiditis. At that time 'the muscle spasm lifted my hips off the bed. No painkillers would touch it'. After six months of bed rest and treatments including morphine and traction, she reported that she weighed about six stone, was unable to feed herself, had pressure sores on her buttocks and heels and wanted to die. Her story illustrated that even in this situation a patient with back pain can attract little sympathy: 'My treatment from the nurses was disgusting. The sister on the ward said to me that I was costing the NHS far too much money. She was talking to me with her head in the drugs trolley and threw the drugs at me onto the bed'.

Those who sought private health care appeared to fare little better. Jane paid to consult a neurosurgeon: 'I felt terribly hard done by... her manner didn't help; very, very dismissive and very sort of abrupt. I didn't feel that she'd put me at my ease, didn't do anything for me. Basically a waste of $£ 100$ '. The consultation left Jane feeling stigmatised on the grounds of age and relative poverty as well as pain. Her experience was similar to one recorded by Charmaz in 1983 [36], suggesting that little had changed since then. The importance of such encounters was noted by Gullacksen and Lidbeck [37] who observed that distrust from health professionals may obstruct the adjustment process and hinder rehabilitation for 
patients with chronic pain. Judith fared even worse in terms of her treatment at the hands of an orthopaedic surgeon by whom she was assessed in connection with an industrial injury claim: 'he seemed determined that he was going to hurt me. ... He clenched his fist and hit me on the top of my head really hard. I burst into floods of tears. He said 'oh, it hurt did it?'. He never asked where it hurt. He didn't even apologise'. Low back problems are stigmatised in the field of sickness benefits and compensation because of the lack of objective diagnostic tests [38]. Pressure on the head was introduced to distinguish those with 'real' back pain from malingerers and ensure correct classification [39]. Judith appeared unaware that she had 'failed' the test and in so doing had acquired a moral stigma which would accompany her on her continuing pain journey. Wessley [40 p. 912] observed: 'If you have to prove you are ill you can't get well', a phenomenon referred to by some authors as 'social iatrogenesis' [41]. Similar findings led Harding et al [42] to assert that loss of trust in the medical profession needs to be addressed when treating chronic pain, or poor outcomes and patient dissatisfaction are likely to continue.

\section{Stigma and work}

Scambler [43] recorded that having a stigmatising condition can lead to changes in circumstance that are stigmatising in their own right. With the exception of Judith, all participants were without employment and financially dependent on either their spouse or social benefits (or both). These forms of support are both stigmatised in the literature on chronic pain through the label of 'secondary gain' 
[44]. But all of our participants described their struggle to retain work and told stories of unsympathetic encounters with employers. Mike recounted: 'when you are working and people can't see that you're physically disabled or that you are in pain, you might be struggling with the pain and the boss will come along and say 'I want this and this done' and he expects you to jump up and do it straight away and mentally you have to get yourself through this pain threshold ... and he'll have another go at you for not being quick at responding'. Being 'off sick' with a bad back has acquired moral stigma amid media reports that it is used as a ruse to live off social benefits. But Reg (aged 53) had lost a series of manual jobs due to his back pain and recounted his most recent experience: 'they [his bosses] were just biding their time. ... I was never late from the time I started there until the day I was dismissed, but I was three minutes late and he just came down and said 'gotcha - out". Reg now accepted that he was unemployable but observed 'I would like to take medical retirement ... it would be nice to actually say to people 'I'm retired' rather than 'I'm off sick". Many participants found themselves not only in conflict with employers, but also avoided by colleagues. Sue told how a former workmate reported hostility at work that she had made a claim for industrial injury, while another former colleague crossed the street, apparently to avoid her. These situations inevitably created mistrust and threatened to damage their concept of self $[45,3]$.

\section{Stigmatisation by 'significant others'.}

Back pain disrupts life for families [46] and some participants attributed the break 
up of their marriage to their back problem. Lack of a diagnostic label and the invisibility of pain also made communication with family and friends difficult, arousing suspicions that the pain was not real. David and Reg shared almost identical experiences: 'My wife even turned on me, thinking it was all put on. She came into the bedroom one morning to find me flat on the floor unable to move and she naturally assumed that I was putting it on. From that point l've just lived on my own' (David). 'My first wife left me on the floor for 48 hours without even giving me my cigarettes, so as soon as I was fit and able I left 'cos it scared me' (Reg). In both cases, the wives expressed disbelief that their husband's response to pain was legitimate. This may have been precipitated by the continuing burden of social limitation and isolation imposed by the pain $[47,48,49]$ or by the inability to tolerate stigma by association [50], but confirms Roy's [51] observation that chronic pain extracts a heavy price on spouses. This includes social isolation, role tension, marital conflict and reduced sexual activity, leading to anger, resentment, anxiety and despondency among family members [52]. Fear of damaging relationships led some of our participants to conceal their true feelings. Jane commented 'I do sometimes think, gosh, some people must think I whinge and I try and when they say 'how are you?', I say 'fine', you now, because nobody really wants to know do they?'. As a result, participants were often tempted to undertake activities that they knew would exacerbate the pain, though this may serve to increase suspicions that there was nothing wrong after all.

\section{Stigmatisation in everyday life}


Goffman showed that people may be stigmatised for how they manifest signs of illness. Geoff (aged 56) regularly attended a private physiotherapy practice where he described the receptionist as 'rather like a guard dog who keeps away the difficult people but lets the nice ones through. If I go into that reception on two sticks she will say 'I don't think the physiotherapist has got time to see you next week'. If I walk in without the sticks she says 'oh yes, when would you like an appointment?'. Appearances count for so much in our society that if you adapt your own behaviour the attitude of a whole range of society towards you changes'. Dewar et al [53] noted that those with chronic pain felt stigmatised because of the invisibility of their pain. Some of our participants' stories suggested that this might be exacerbated by media representations of 'benefit frauds' that are seen to threaten social order [43]. Peter (aged 38) had problems after he acquired a specially adapted car at a discount price: 'Next door started because I've got a motability car. I've had letters put through my door cut from papers: 'social security swindlers, tax dodgers', you name it l've had it all put through my door. I have a disabled bay out there for my use because I could not walk- it was too bad, and it was rejected because people objected to it, don't ask me why... because they see me walking around as far as they're concerned I'm not disabled, but have they gone through what I've gone through? I wouldn't like to put anybody through it, no way'. Sue used a disabled badge to signify her right to park in a non-parking zone. 'I went into [town] about 3 months ago, I was picking up my benefit. I was parking along the street - two young 17and 18 yearolds were making lewd remarks and when I put my orange disability badge on 
the screen, they spat on my windscreen. I went straight home. I felt like nothing and that is what people view you as'. Reg's observable pain behaviours attracted police attention on a number of occasions: 'I think in the last 12 months I've been stopped 6 times [because] I get out of the car at these garages [to fill up with petrol] and I sort of walk the side of the car with my hands to stand up straight and they think I'm drunk, which is quite funny because I don't drink at all, not even at Christmas'. Accounts such as these highlight the extent of stigmatisation caused by manifest signs of disability caused by an 'invisible' condition such as back pain. They also highlight dilemmas confronted by participants in their everyday lives.

Jane contrasted public reactions to visible injury with those to invisible back pain: 'When I had a broken arm, it was wonderful, they all rushed towards me to help me in the supermarket and I didn't feel a bit guilty because it was in a plaster and in a sling and it was OK and I didn't mind. But now you do, to all intents and purposes, look perfectly alright and you do feel a bit of a fool and some of the other people just look at you and you just feel guilty about it all. Do they think I'm a fraud perhaps? I don't know, if something showed it might be easier but it is depressing ... you're afraid of what people think'. Jane switched from 'I' when talking about herself with a broken arm to 'you' when talking about herself with a bad back as if trying to distance herself. Hilbert [50] and Joachim and Acorn [54] have highlighted difficulties of managing 'invisible' pain in social settings, particularly the need to balance disclosure and concealment. Steve (aged 44) 
illustrated some important dilemmas: 'l've got the pain and nobody can point to anything and that's why people can say 'is it up in his head? He can't be in so much pain'. You see someone with their arm in plaster then you can see there's something wrong with them, but when someone asks me to do something and they can't see it, I do get quite a lot of stick from friends. Sometimes I use a walking stick and sometimes I don't and if I don't have the stick nobody can see the problems and they don't think there's a problem so they'll ask you to do somethink [sic] and if you turn round and say no, they say 'what's wrong with him?', so I tend to do it. Examples is a woman broke down in her car, I'll push start it; or see a lady struggling with a pushchair on a bus, I'll take it off'. Jacoby et al. [55] suggested that stigma might be regarded as a self-fulfilling prophecy because people respond to what they assume to be the negative attitudes of others.

Stigmatisation, or fear of stigmatisation, emerged as an important reason for the 'loss of self', described by Charmaz [36] as leading to social isolation. The stigma of 'invisible' and discredited illness leads to feelings of shame [56] and emerged in our study as an important cause of suffering among those with chronic back pain. Younger [57] pointed out that those suffering from chronic pain are consistently alienated from communities that might provide support, disconnected by their inability to communicate their suffering or to accept help and by the desire of others to see suffering alleviated but not to get too involved. Carol, aged 38 and a (former) nurse, summed up these dilemmas in her everyday life: 'I feel I 
should be able to do things but I can't. People must think you use it as an excuse. My friends know me for who I am. Society in general will think I am making excuses. Because I'm not in a wheelchair I haven't got anything that they can actually see. I think they feel that you are pulling the wool over their eyes. They don't know what it's really like. They don't know what it's like to be trapped in your own home for weeks on end and not be able to go anywhere. I only half accept it. My mind is telling me 'you should be doing this and that', but my body is telling me the exact opposite. I almost think it makes you become two people'.

\section{Discussion}

'Stigma' was documented by Goffman in the 1960s and has since been widely applied to groups suffering from a variety of physical and mental conditions including chronic illness [58]. Although chronic back pain is not itself visible, its behavioural manifestations, including help-seeking, can be perceived in everyday life through interaction with others. But as previous authors have noted, it is the very invisibility of pain that brings about most of the problems of being 'discredited' [59]. The stigmatisation of those with chronic pain is evident in $20^{\text {th }}$ Century literature which sought to identify the 'pain-prone personality' [60] and attribute pain complaints to secondary gain [61]. As a result, those with 'chronic pain syndrome' are subject to disbelief by the lay public as well as professionals who label these patients as psychologically damaged or deviant. Resistance of these stigma appeared to lead some of our participants to engage in activities, such as helping others, likely to exacerbate their pain. 
These participants were at the point of entry into a service that is often regarded by those with chronic pain as their 'last resort'. However, as Eccleston et al [28] documented, the beliefs of patients and health professionals may be diametrically opposed - patients seeking biomechanical explanations and medical treatments, and professionals offering psychological explanations and interventions. Patients attending pain clinics are often confronted by mixed messages. The sign over one such clinic reads 'Pain Relief Clinic', indicative of an environment that encourages the sick role $[59,12]$. The chronic pain treatment model has only recently changed to one of self-management, rather than cure $[62,63]$. No wonder patients may feel confused and dismayed by their interactions with health care professionals [28]. Reg's story of humiliation in hospital illustrated how patients may be caught, unknowingly, in this paradigm shift. Other accounts illustrated how, prior to treatment in the pain clinic, there may exist a tension between the desire for diagnosis and acknowledgment of their 'condition', and the aspiration to discard the sick role and regain a former sense of identity. These hopes are unlikely to be fully realised, though lack of acceptance and continued complaints of pain stigmatise this patient group as non-compliant or negativistic [64].

Kleinman [18] recorded that the victim of chronic pain may be shunned and degraded, but also noted ( $p$ 160) that the individual can either accept or reject the stigmatised identity. Scambler argued that 'collective negative representations of 
deviance' [43] conspire to damage self-esteem. Yet it is clear that not everyone with a particular condition feels stigmatised [65], and Crocker and Quinn [66] have challenged the notion that stigmatisation is necessarily associated with lowering of self-esteem. We certainly observed variations in the ways in which participants construed the meaning of events and it is noteworthy that the only person who appeared to reject feelings of self-blame or shame was the youngest and most disabled participant (Sue) whose accounts contained the worst examples of stigmatising experiences. The main differences between Sue and the others appeared to be her relative affluence and family support, combined with a recognised medical diagnosis which afforded a degree of credibility not available to the others. Nevertheless, our findings have clearly illustrated some of the social difficulties that pervade the lives of many people who have chronic back pain. Similar issues led Jacoby et al. [55] to propose that stigma is potentially a major, though not easily quantifiable, burden for those with chronic illness. The effects of stigma were experienced at a material as well as a psychological level, both of which are capable of leading to feelings of inadequacy and shame [58]. The findings of our study appear to support the claim of Roy [30] that there is a 'prima facie' case for accepting that depression of chronic pain patients is congruent with their life experiences and feelings of being seen as discredited. It is perhaps surprising, therefore, to find that stigma does not appear in the indices of any important analytic texts on pain $[67,68]$.

Given these findings, it would seem important that the management of personal 
identity in the context of social interactins are addressed in pain management programmes. In reviewing the key characteristics of pain management programmes, it would appear that their content is very variable [69], though Ospina and Horstall [70] identified that the aims and key components tend to focus predominantly on functional restoration. Although the emphasis of pain management has continued to shift towards self-management, the most important outcome measures remain 'return to work' [71] along with improvements in function and pain reduction. The findings of our study highlight the importance of addressing how to deal in a practical way with the social situations individuals with back pain encounter during their daily lives [18]. This is similar to the findings of a qualitative study of those undertaking a multiprofessional rehabilitation programme for fibromyalgia [72] which identified as its core category the transition from shame to respect. Important aspects of intervention included finding ways of explaining their pain to others and learning how to say 'no' when faced with demands from others that would involve going beyond their limits. Our findings support the view that listening and believing are important motivational aspects of the therapeutic process [73] and that dealing with stigma should be included as part of cognitive behavioural pain management programmes.

In reviewing the credibility (validity) of our findings, it is necessary to consider the trustworthiness of data obtained through unstructured narrative interviews. Werner et al. [13] suggested that narratives of chronic pain contain a 'moral plot' 
in which, because of past scepticism and distrust, participants attempt to convince the audience of the legitimacy of their illness story. Likewise, Ong et al. [11] noted that the stories of their interviewees with low back pain were oriented towards a construction of the self as credible in a moral sense. It is difficult to know if the accounts we have reproduced reflect 'real' events, or if they are created or 'performed' in response to a need for self-justification [32]. The strong commonalities of experience within our data, combined with extant research findings, have led us to the interpretation that those seeking help for chronic benign back pain have had to deal with a variety of stigmatising attitudes and situations, often over many years, that are likely to challenge their sense of identity and self-worth and stimulate the need for self-justification.

In conclusion, our findings suggest that stigmatisation, whether real or feared, is an important reason why people with chronic back pain find it difficult to adapt to their situation. Stigmatisation is reinforced by media portrayals as well as public and professional beliefs, attitudes and behaviours, and may account in some measure for the lowering of self-worth and feelings of shame with or without depression, often observed in people who have chronic back pain. Avoidance of stigmatisation may lead to either to concealment and social isolation, or to risk behaviours that exacerbate pain. A number of researchers have identified the need for further studies to understand the interrelationship of psychosocial factors in chronic pain and to integrate them into a conceptual framework [71, 74]. Based on our findings, we suggest that pain theories could be strengthened 
by including social perceptions, such as stigmatisation, as mediators of depression in chronic back pain. We also propose that pain management programmes need to confront the realities and practicalities of dealing with potentially stigmatising interactions in everyday life. 


\section{References}

1. Truchon M. Determinants of chronic disability related to low back pain:

Towards an integrative biopsychosocial model. Disability and Rehabilitation 2001;23(17):758-767.

2. Frischenschlager O, Pucher I. Psychological management of pain. Disability and Rehabilitation 2002;24(8):416-422.

3. Walker JM, Sofaer B, Holloway IM. The experience of chronic back pain: accounts of loss in those seeking help from pain clinics. European Journal of Pain 2006;10(3):199-207.

4. Ericsson M, Poston WSC, Linder J, Taylor JE, Haddock CK, Forey JP. Depression predicts disability in long-term chronic pain patients. Disability and Rehabilitation 2002;24(6):334-340.

5. Bowman JM. The meaning of chronic low back pain. AAOHN 1991;39(8):3814.

6. Bowman JM. Reactions to chronic low back pain. Issues in Mental Health Nursing 1994;15:445-53.

7. Osborne M, Smith JA. The personal experience of chronic benign lower back pain: an interpretative phenomenological analysis. British Journal of Health Psycholology 1998;3:65-83.

8. Seers K, Friedli K. The patients' experiences of their chronic non-malignant pain. Journal of Advanced Nursing 1996;24:1160-1168.

9. Bendelow GA, Williams $S$. The end of the road? Lay views on a pain-relief clinic. Social Science and Medicine 1996;43:1127-1136. 
10. Lillrank A. Back pain and the resolution of diagnostic uncertainty in illness narratives. Social Science and Medicine 2003;57:1045-54.

11. Ong BN, Hooper H, Dunn K, Croft P. Establishing self and meaning in low back pain narratives. Sociology Review 2004;52:532-49.

12. Werner A, Steihaug S, Malterud K. Encountering the continuing challenges for women with chronic pain: Recovery through recognition. Qualitative Health Research 2003;13(4):491-509.

13. Werner A, Isaksen LW, Malterud K. I'm not the kind of woman who complains of everything: Illness stories on self and shame in women with chronic pain. Social Science and Medicine 2004;59:1035-45.

14. Walker J, Holloway I, Sofaer B. In the system: the lived experience of chronic back pain from the perspective of those seeking help from pain clinics. Pain 1999;80:621-628.

15. Smith JA. Beyond the divide between cognition and discourse: using interpretative phenomenological analysis in health psychology. Psychology and Health 1996;11:261-271.

16. Smith JA. Reflecting on the development of interpretative phenomenological analysis and its contribution to qualitative research in psychology. Qualitative Research in Psychology 2004;1(1):39-54.

17. Smith JA, Osborn M. Interpretative phenomenological analysis. In Smith JA, editor. Qualitative Psychology: A Practical Handbook. London: Sage, 2003, pp. $51-80$ 
18. Kleinman A. The illness narratives: suffering, healing and the human condition. New York: Basic Books, 1988.

19. Kvale S. Interview: an introduction to qualitative research interviewing. Newbury Park: Sage, 1996.

20. Lincoln YS, Guba E. Naturalistic Enquiry. Beverly Hills, CA: Sage, 1985.

21. Morse J. Designing funded qualitative research. In Denzin NK, Lincoln YS, editors. Handbook of Qualitative Research. Thousand Oaks, CA: Sage, 2004, pp. $220-235$.

22. Goffman E. Stigma. Notes on the management of Spoilt Identity. Englewood Cliffs, NJ: Prentice Hall, 1963.

23. Deyo RA. Low back pain. New England Journal of Medicine 2001;344:363.

24. Baszanger I. Deciphering chronic pain. In Strauss A, Corbin J, editors. Grounded Theory in Practice. Newbury Park: Sage, 1997, pp. 1-33.

25. Taylor MC. Stigma: theoretical concept and actual experience. British Journal of Occupational Therapy 1991;54:406-10.

26. Diamond EL, Grauer K. The physician's reactions to patients with chronic pain. American Family Physician 1986;34:117-122.

27. May CR, Rose MJ, Johnstone FCW. Dealing with doubt: How patients account for non-specific chronic low back pain. Short report. Journal of Psychosomatic Research 2000;49:223-225.

28. Ecclestone C, De Williams AC, Stainton Rogers W. Patients and professionals understanding of the causes of chronic pain: blame, 
responsibility and identity protection. Social Science and Medicine 1997;5:699-709.

29. Jackson JE. "After a while no one believes you": real and unreal pain. In Good M-JD, Brodwin PE, Good BJ, Kleinman A, editors. Pain as human experience: an anthropological perspective. Berkeley: University of California Press, 1992, pp. 138-168.

30. Roy R. Social relations and chronic pain. New York: Kluwer/Plenum, 2001.

31. Cassell EJ. The nature of suffering and the goals of medicine, 2nd edition. Oxford: Oxford University Press, 2004.

32. Werner A, Malterud K. It is hard work behaving as a credible patient: encounters between women with chronic pain and their doctors. Social Science and Medicine 2003;57:1409-1419.

33. Fordyce WE. Back pain in the workplace: management of disability in nonspecific conditions. Seattle: IASP Press, 1995.

34. Parsons T. The social system. Glencoe, IL: Free Press, 1951.

35. Stockwell F. The unpopular patient. London: Croom Helm, 1984.

36. Charmaz K. Experiencing chronic illness. In Albrecht GL, Fitzpatrick R, Scrimshaw SC, editors. Handbook of Social Studies in Health and Medicine. London: Sage, 2000, pp. 277-92.

37. Gullackson AC, Lidbeck J. The life adjustment process in chronic pain: psychosocial assessment and clinical implications. Pain Research and Management 2004;9:145-53. 
38. Alexanderson K, Norland A. Chapter 1: Aim, background, key concepts, regulations, and current statistics. Scandinavian Journal of Public Health 2004;32(Suppl 63):12-30.

39. Dunbar D. Defining non-diseases to avoid medicalisation is throwing the baby out with the bath water. British Medical Journal 2002;324:912.

40. Wessley S. What do you think is a non-disease? British Medical Journal 2002;324:912.

41. Quintner JL. The Australian RSI debate: stereotyping and medicine. Disability and Rehabilitation 1995;17:256-62.

42. Harding G, Parsons S, Rahman A, Underwood M. It struck me that they didn't understand pain: The specialist pain clinic experience of patients with chronic musculoskeletal pain. Arthritis and Rheumatism (Arthritis Care \& Research) 2005;53(5):691-696.

43. Scambler G. Perceiving and coping with stigmatising illness. In Fitzpatrick R, Hinton J, Newman S, Scambler G, Thompson J, editors. The experience of illness. London: Tavistock, 1988, pp. 203-226.

44. Dersh J, Polatin PB, Leeman G, Gatchel RJ. The management of secondary gain and loss in medicolegal settings: strengths and weaknesses. Journal of Occupational Rehabilitation 2004;14: 267-79.

45. Kelly M, Field D. Medical sociology, chronic illness and the body. Sociology of Health and Illness 1996;18:241-57.

46. Bral E, Shaughnessy MF, Eisenman R. Intimacy in people with chronic pain. International Journal of Psychosocial Rehabilitation 2002;6:51-60. 
47. Miller J, Timson D. Exploring the experiences of partners who live with a chronic low back pain sufferer. Health and Social Care in the Community, 2004;12(1):34-42.

48. Smith AA, Friedman M. Perceived family dynamics of person with chronic pain. Journal of Advanced Nursing 1999;30(3):543-551.

49. Strunin L, Boden LI. Family consequences of chronic back pain. Social Science and Medicine 2004;58:1385-1393.

50. Hilbert RA. (1984) The cultural dimensions of chronic pain: flawed reality construction and the problem of meaning. Social Problems1984;31:365-78.

51. Roy R. The social context of the chronic pain sufferer. Toronto: University of Toronto Press, 1992.

52. Snelling J. The effect of chronic pain on the family unit. Journal of Advanced Nursing 1994;9:543-51.

53. Dewar A, White M, Santiago T, Posade MD, Wilson D. Using nominal group technique to assess chronic pain, patients perceived challenges and needs in a community health region. Health Expectations 2003;6:44-56.

54. Joachim G, Acorn S. Stigma of visible and invisible chronic conditions. Journal of Advanced Nursing 2000;32:243-48.

55. Jacoby A, Snape D, Baker GA. Epilepsy and social identity: the stigma of a chronic neurological disorder. Lancet Neurology 2005;4:171-78.

56. Pierret J. The illness experience: state of knowledge and perspectives for research. Sociology of Health and Illness 2003;25:4-22. 
57. Younger JB. The alienation of the sufferer. Advances in Nursing Science 1994;17:53-72.

58. Charmaz K. Loss of self: a fundamental form of suffering in the chronically ill. Sociology of Health and Illness 1983;5:168-95.

59. Glenton C. Chronic back pain sufferers: striving for the sick role. Social Science and Medicine 2003;57:2243-2252.

60. Engel GL. "Psychogenic" pain and the pain-prone personality. American Journal of Medicine 1959;26:899-918.

61. Fishbain DA, Rosomoff HL, Cutler RB, Rosomoff RS. Secondary gain concept: a review of the scientific evidence. Clinical Journal of Pain 1995;11:6-21.

62. Lorig KR, Sobel DS, Stewart AL, Brown BWJr, Bandura A, Ritter P, Gonzalez VM, Laurent DD, Holman HR. Evidence suggesting that a chronic disease self-management program can improve health status while reducing hospitalization: a randomised trial. Medical Care 1999;37:5-14.

63. Department of Health. The expert patient: a new approach to chronic disease management for the 21st century. London: HMSO, 2001.

64. Kodiath MF. A new view of the chronic pain patient. Holistic Nursing Practice 1991;6:41-46.

65. Baker GA. People with epilepsy: what do they know and understand, and how does this contribute to their perceived level of stigma. Epilepsy and Behaviour 2002;3(6S2):26-32. 
66. Crocker J, Quinn DM. Psychological consequences of devalued identities. In Brown R, Gaertner S, editors. Handbook in Social Psychology. Malden, MA: Blackwell, 2001, pp. 238-257.

67. Good M-JD, Brodwin PE, Good BJ, Kleinman A, editors. Pain as human experience: an anthropological perspective. Berkeley: University of California Press, 1992.

68. Gatchel RJ, Turk DC, editors. Psychosocial factors in pain: critical perspectives. New York: The Guilford Press, 1999.

69. Guzmán J, Esmail R, Karjalainen K, Malmivaara A, Irvin E, Bombardier C. Multidisciplinary rehabilitation for chronic low back pain: systematic review. British Medical Journal 2001;322:1511-1516.

70. Ospina M, Harstall C. Multidisciplinary pain programs for chronic pain: evidence from systematic reviews. Alberta: Alberta Heritage Foundation for Medical Research, HTA 30: Series A Health Technology Assessment, 2003.

71. Pincus T, Burton AK, Vogel S, Field AP. A systematic review of psychological factors as predictors of chronicity/disability in prospective cohorts of low back pain. Spine 2002;27:109-120.

72. Gustafsson M, Ekholm J, Ohman A. From shame to respect: musculoskeletal pain patients' experience of a rehabilitation programme, a qualitative study. Journal of Rehabilitation Medicine 2004;36:97-103.

73. Jensen MP, Nielson WR, Kerns RD. Toward the development of a motivational model of pain self-management. The Journal of Pain 2003;4(9):477-492. 
74. Truchon M, Fillion L. Biopsychosocial determinants of chronic disability and low-back pain: a review. Journal of Occupational Rehabilitation 2000;10:117142. 